\title{
Optical characterization of muscle
}

\author{
Luís Oliveira $^{* a, b}$, Armindo Lage ${ }^{c}$, Manuel Pais Clemente ${ }^{b}$ and Valery V. Tuchin ${ }^{d}$ \\ a Physics Department, Instituto Superior de Engenharia do Porto, Rua Dr. António Bernardino de \\ Almeida, No 431, 4200-072 Porto, Portugal; \\ ${ }^{*}$ CETO - Centro de Ciências e Tecnologias Ópticas, Rua Caldas Xavier, $N^{\circ} 38-6^{\circ}$ E, 4150 Porto, \\ Portugal; \\ ${ }^{c}$ Department of Electrical and Computer Engineering, Porto University - School of Engineering, \\ Rua Dr. Roberto Frias, 4200 - 465 Porto, Portugal; \\ ${ }^{\mathrm{d}}$ Research Educational Institute of Optics and Biophotonics, Saratov State University \\ 83 Astrakhanskaya str., Saratov 410012, Russia
}

\begin{abstract}
Optical characterization and internal structure of biological tissues is highly important for biomedical optics. In particular for optical clearing processes, such information is of vital importance to understand the mechanisms involved through the variation of the refractive indices of tissue components. The skeletal muscle presents a fibrous structure with an internal arrangement of muscle fiber cords surrounded by interstitial fluid that is responsible for strong light scattering. To determine the refractive index of muscle components we have used a simple method of measuring tissue mass and refractive index during dehydration. After performing measurements for natural and ten dehydration states of the muscle samples, we have determined the dependence between the refractive index of the muscle and its water content. Also, we have joined our measurements with some values reported in literature to perform some calculations that have permitted to determine the refractive index of the dried muscle fibers and their corresponding volume percentage inside the natural muscle.
\end{abstract}

Keywords: Tissue optical properties; Tissue optics; Muscle; Refractive index mismatch; Scattering; Tissue optical clearing.

\section{INTRODUCTION}

One major objective in Biophotonics research is the optimization of light propagation inside biological tissues so the optical techniques can be fully used in clinical practice. To achieve such optimization it is first necessary to study and understand the difficulties that the nature of tissues imposes to light propagation. Only then we can plan and take corrective measures to optimize the action of light in clinical procedures.

Every biological tissue presents two phenomena when in contact with light: tissues absorb and scatter light ${ }^{1}$. Attending to the magnitude of the absorption and scattering coefficients of typical biological tissues, we observe that light is highly scattered than absorbed ${ }^{1,2}$. In face of this difference between the two phenomena, the scattering of light is considered the main obstacle to light propagation in biological tissues.

To better understand why scattering is so strong in biological tissues (typically scattering coefficient is $10-20$ times the absorption coefficient ${ }^{1}$ ), we need to understand the cause of such high scattering. The scattering of light in biological tissues is originated into two independent ways. First, biological tissues contain elements, like muscle fibers, vesicles, cells, organelles and other components that scatter light. On the other hand, the heterogeneous composition of biological tissues (local variations of refractive index) originates also light scattering. By analyzing the two causes of light scattering, we verify that the first cannot be controlled without harming the tissue constitution. On the other hand, the second can be controlled without harming the tissue, by using the optical clearing treatment. With this method in particular we can optimize the propagation of light inside biological tissues. Research concerning the tissue immersion method for optical clearing has proven to be very effective ${ }^{3,4}$.

Saratov Fall Meeting 2011: Optical Technologies in Biophysics and Medicine XIII, edited by Valery V. Tuchin,

Elina A. Genina, Igor V. Meglinski, Proc. of SPIE Vol. 8337, 833705 · C 2012 SPIE

CCC code: $1605-7422 / 12 / \$ 18 \cdot$ doi: $10.1117 / 12.924213$

Proc. of SPIE Vol. 8337 833705-1 
To explain the optical clearing effects observed experimentally, it is necessary to know the internal composition and the refractive index profile of the natural tissue ${ }^{3}$. At optical clearing, the internal composition of tissues changes, and the variations in the absorption $\left(\mu_{\mathrm{a}}\right)$ and scattering $\left(\mu_{\mathrm{s}}\right)$ coefficients of the tissue cause the time-dependence of the refractive index profile.

Two mechanisms occur at optical clearing: tissue dehydration and refractive index matching, but the occurrence sequence was not known before our study ${ }^{3,4}$. We have discovered that an osmotic pressure is created by the optical clearing agent that forces water to leave from the interstitial spaces of the tissue. Such water leaves the tissue and though tissue dehydration takes place at the beginning. Only after the occurrence of tissue dehydration the optical clearing agent permeates the tissue occupying the interstitial volume that was previously filled by water ${ }^{4}$.

Since we were interested in studying the optical clearing treatment of muscle samples, we first needed to study the muscle's internal composition and determine the magnitude of its refractive index profile. To do this, we had to adopt an experimental methodology that could allow us to discriminate the refractive indices of muscle components and also determine their volume fractions. The next section contains the description of such methodology.

\section{METHOLOGY}

We have selected the abdominal wall muscle from the Wistar Han rat to perform our studies. Such is a fibrous tissue with strong scattering properties, as we can see from figure 1 :

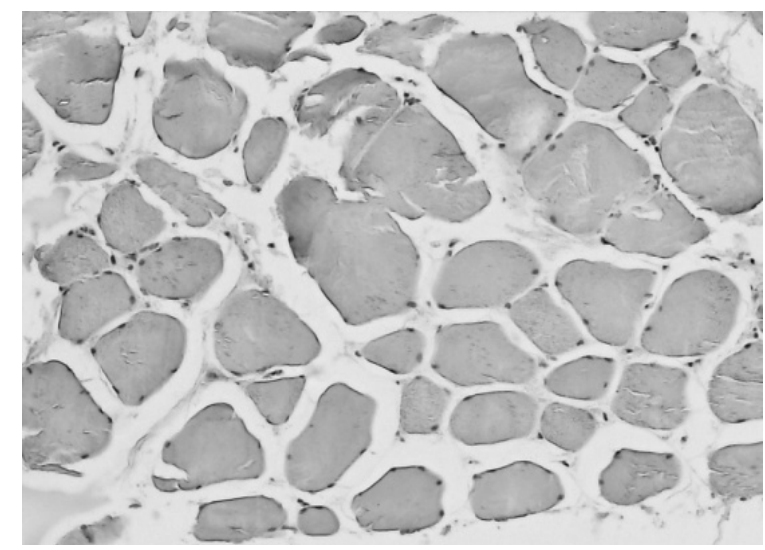

Figure 1: Cross-section of abdominal wall muscle from rat (species Wistar-Han)

In figure 1, we can clearly see the muscle fiber cords (in dark grey) surrounded by the interstitial fluid (in light grey).

After dissecting the muscle block from the animal, we have prepared our samples with desired geometry and thickness so they could be used in one dehydration study. The individual samples were sliced from the abdominal muscle block with $0.4 \mathrm{~mm}$ thickness. Such thickness was previously verified to be adequate for the refractive index measurements with the Abbe refractometer. After obtaining two samples we have proceeded with our study that consisted in measuring the refractive index and mass of the sample for natural and consecutive dehydration states. The measurements were first made for natural tissue. Refractive index of the sample was measured with red contrast illumination in the Abbe refractometer. The sample mass was obtained by placing the natural sample in a precision weighting scale. After obtaining this pair of measurements from the natural tissue, dehydration was applied to the sample with a hairdryer and a new pair of measurements was obtained from the first dehydrated state. Such method was repeated until we had measurements from 10 dehydrated states. The hairdryer was always applied to the muscle sample for a period of about 50 seconds to 1 minute and from the same distance.

After collecting these pairs of measurements for natural and dehydrated states, we could perform calculations to estimate the volume fractions and refractive indices of the muscle components, here designated by dry matter and water. The calculations here so indicated are presented and explained in section four. 


\section{EXPERIMENTAL MEASUREMENTS}

Following the experimental method described in section 2 and selecting one muscle sample with $0.4 \mathrm{~mm}$ thickness, we have obtained the refractive index and mass measurements from the natural sample and from the sequential dehydrated states. These experimental values are represented in table 1:

Table 1: Mass and refractive index values of the tissue measured during dehydration

\begin{tabular}{|c|c|c|}
\hline Dehydration state & Refractive index & Mass (g) \\
\hline Natural & 1.3980 & 0.1623 \\
\hline 1 & 1.3995 & 0.1455 \\
\hline 2 & 1.4105 & 0.1361 \\
\hline 3 & 1.4200 & 0.1252 \\
\hline 4 & 1.4295 & 0.1144 \\
\hline 5 & 1.4410 & 0.1053 \\
\hline 6 & 1.4525 & 0.0955 \\
\hline 7 & 1.4640 & 0.0860 \\
\hline 8 & 1.4785 & 0.0747 \\
\hline 9 & 1.4910 & 0.0654 \\
\hline 10 & 1.5035 & 0.0551 \\
\hline
\end{tabular}

With the measurements presented in table 1 we can represent the dependency between the refractive index and mass of the sample during dehydration:

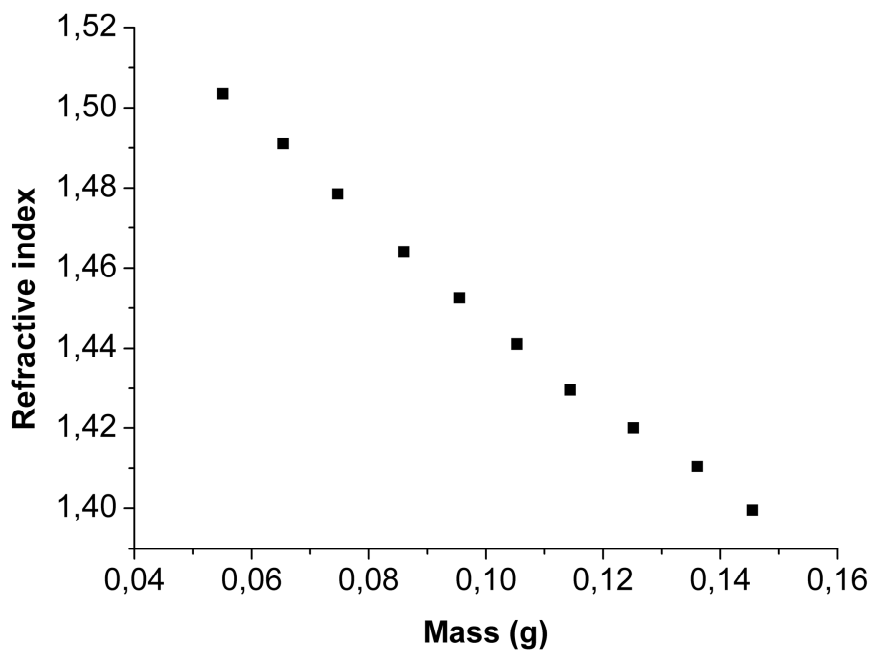

Figure 2: Refractive index - mass dependence of the muscle sample during dehydration

As we can verify from figure 2, the dependency is almost linear and the refractive index of the sample rises for lower sample's mass. In other words, the refractive index increases with the dehydration of the sample. Additionally to the determination of such dependence, we can also perform some calculations to estimate the refractive indices and volume fractions of muscle components. Such calculations are presented in section 4. 


\section{CAlculations}

According to the law of Gladstone and Dale, the refractive index of a biological tissue is a weighted combination of the refractive indices of the tissue components ${ }^{3}$ :

$$
n_{\text {natural }}=f_{\text {water }} n_{\text {water }}+f_{\text {dry }} n_{\text {dry }} .
$$

Additionally, the volume fractions of tissue components, when summed together, must equal the total volume of the tissue sample ${ }^{3}$ :

$$
f_{\text {water }}+f_{\text {dry }}=1
$$

As we can observe in figure 1, the skeletal muscle from the abdominal wall of rat is a fibrous tissue composed by a collection of muscle fiber cords distributed through the interstitial fluid. Such fluid is located in-between the fiber cords and also inside the cords. It is mainly composed by water, but it also contains a small percentage of salts and minerals. The muscle fiber cords cross-sections are well seen in figure 1, being surrounded by the interstitial fluid.

The volume fraction of water in rat muscle is indicated in literature as $0.756^{5}$. The refractive index of water in natural rat skeletal muscle can be calculated for a specific wavelength by equation $3^{3}$ :

$$
n_{\text {water }}(\lambda)=1.31848+\frac{6.662}{\lambda-129.2} \text {. }
$$

Considering the Abbe refractometer that we have used to measure the refractive index of the muscle samples, the reference wavelength is $589 \mathrm{~nm}$. For this wavelength, equation 3 gives 1.3330 for the refractive index of water.

Since the density of water is $1 \mathrm{~g} / \mathrm{cm}^{3}$, we can consider that the density $(\rho)$ of a material is defined in $\mathrm{g} / \mathrm{cm}^{3}$ by equation 4:

$$
\rho=\frac{\text { mass }}{V o l} .
$$

By interchanging volume and density in equation 4, we obtain an expression to determine the volume as a function of mass and density.

In the case of natural rat muscle, we can also write the volume fraction of water as the ratio of water volume and sample volume:

$$
f_{\text {water natural }}=\frac{V_{W}}{V_{\text {sample-natural }}} .
$$

Tissue water mass is the difference between natural sample and completely dehydrated sample mass. Using this fact, considering equation 4 and using the densities of water $\left(\rho_{W}\right)$ and dry matter $\left(\rho_{d r y}\right)$, equation 5 takes the form ${ }^{6}$ :

$$
f_{\text {water natural }}=\frac{\left(\text { mass }_{\text {natural }}-\text { mass }_{d r y}\right) \rho_{W}^{-1}}{\rho_{W}^{-1}\left(\text { mass }_{\text {natural }} \text { mass }_{\text {dry }}\right)+\rho_{\text {dry }}^{-1} \text { mass }_{d r y}} .
$$

Since $\rho_{W}=1$, the previous equation can be simplified:

$$
f_{\text {water natural }}=\frac{\text { mass }_{\text {natural }}-\text { mass }_{d r y}}{\text { mass }_{\text {natural }}-\left(1-\rho_{\text {dry }}^{-1}\right) \text { mass }_{d r y}} .
$$

Performing a similar deduction, the volume fraction of the dry matter in the natural sample can be calculated by the following equation: 


$$
f_{\text {dry }}^{\text {natural }}=\frac{\rho_{\text {dry }}^{-1} \text { mass }_{\text {dry }}}{\text { mass }_{\text {natural }}-\left(1-\rho_{\text {dry }}^{-1}\right) \text { mass }_{d r y}} .
$$

In each dehydrated state of the tissue in which we have taken experimental measurements, we need corrected versions of equations 7 and 8 to determine the volume fractions of water and dry matter. This way, for each dehydrated state $i$ of the tissue, we consider the following relations:

$$
\begin{aligned}
f_{\text {water }}^{i} & =\frac{\text { mass }^{i}-\text { mass }_{d r y}}{\text { mass }^{i}-\left(1-\rho_{d r y}^{-1}\right) m a s s_{d r y}} . \\
f_{d r y}^{i} & =\frac{\rho_{d r y}^{-1} m^{i} a s s_{d r y}}{m_{a s s}{ }^{i}-\left(1-\rho_{d r y}^{-1}\right) m_{a s s} d r y} .
\end{aligned}
$$

At every tissue state (natural or dehydrated) the sum of the volume fractions in equations 9 and 10 must be equal to 1 . To calculate the volume fractions of dry matter and water for each dehydrated state with the previous equations, we have used the measurements presented in table 1.

In these equations we have two unknown parameters: dry matter density and dry matter mass. We do know that these parameters do not change during dehydration. By the time we have performed this study, the dry matter density of rat muscle had not been already reported. On the other hand, some researchers have reported some values for no fat bovine muscle $7,8,9$. These values were used in our calculations as the best approximation available. We can calculate the dry matter volume fraction from the water volume fraction of 0.756 that has been reported ${ }^{5}$.

In the following calculations, we will use the available data to estimate the variation of sample water content in the dehydration process. Using the natural water volume fraction of rat muscle, along with the dry matter density of no fat bovine muscle in equation 6 , we have determined the dry matter mass for rat muscle. We have performed this calculation twice, considering both the dry matter density values measured by different research groups ${ }^{8,9}$.

According to data from the first group of researchers, bovine muscle presents a dry matter density of $\rho\left(\mathrm{g} / \mathrm{cm}^{3}\right)=$ $1.55-0.349 \times 10^{-3} \mathrm{~T}$, with $\mathrm{T}$ representing the absolute temperature of the sample (measured in Kelvin) ${ }^{8}$. For $27^{\circ} \mathrm{C}$ $(300 \mathrm{~K})$ and dry matter density of $1.446 \mathrm{~g} / \mathrm{cm}^{3}$, we obtain a dry mass of $0.0516 \mathrm{~g}$.

Another group has reported a density of $1.348 \mathrm{~g} / \mathrm{cm}^{3}$ for the dry matter of bovine muscle at $10{ }^{\circ} \mathrm{C}(283 \mathrm{~K}){ }^{9}$. This data corresponds to $0.0492 \mathrm{~g}$ of dry matter mass in our case.

Based on the previous calculated values, we have determined the refractive index of dry matter for each tissue state (natural and dehydrated). For these calculations, we have used the following derivation of equation 1:

$$
n_{\text {dry }}^{i}=\frac{n_{\text {sample }}^{i} n_{\text {water }} f_{\text {water }}^{i}}{1-f_{\text {water }}^{i}}
$$

Table 2 contains the calculated refractive index values for dry matter and water content in each dehydrated state according to data from the first research group ${ }^{8}$ :

Table 2: Calculated values for water content and dry matter refractive index during dehydration based on data from reference 8

\begin{tabular}{|c|c|c|c|c|c|c|c|c|c|c|c|}
\hline \multicolumn{10}{|c|}{ Dample state } \\
\hline \multicolumn{10}{|c|}{ Natural } & \multicolumn{10}{|c|}{ Dehydrated } \\
\hline & & $i=1$ & $i=2$ & $i=3$ & $i=4$ & $i=5$ & $i=6$ & $i=7$ & $i=8$ & $i=9$ & $i=10$ \\
\hline$f_{\text {water }}^{i}$ & 0.7560 & 0.7245 & 0.7030 & 0.6734 & 0.6376 & 0.6007 & 0.5515 & 0.4907 & 0.3929 & 0.2788 & 0.0893 \\
\hline$n_{\text {dry }}^{i}$ & 1.5995 & 1.5742 & 1.5939 & 1.5995 & 1.5993 & 1.6036 & 1.5996 & 1.5902 & 1.5727 & 1.5521 & 1.5203 \\
\hline
\end{tabular}


This way we have calculated the mean and standard deviation of the refractive index for the dry matter of rat muscle, using the following two equations ${ }^{10}$ :

$$
\begin{gathered}
\overline{n_{d r y}}=\frac{1}{N} \sum_{i=1}^{N} n_{d r y}^{i} . \\
s d\left(n_{d r y}\right)=\sqrt{\frac{1}{N-1} \sum_{i=1}^{N}\left(n_{d r y}^{i}-\overline{n_{d r y}}\right)^{2}} .
\end{gathered}
$$

The results from these calculations were:

$$
\overline{n_{d r y}}=1.5823, \quad s d\left(n_{d r y}\right)=0.0260 .
$$

We have performed a similar calculation to estimate the refractive index of the dry matter of rat muscle, but now based on data from the other research group ${ }^{9}$. Once again, using our mass measurements during dehydration and performing a similar calculation, we have determined the volume fractions of water and the refractive index of the dry matter for all the dehydration states of the muscle. The results are presented in table 3:

Table 3: Calculated values for water content and dry matter refractive index during dehydration based on data from reference 9

\begin{tabular}{|c|c|c|c|c|c|c|c|c|c|c|c|}
\hline \multicolumn{10}{|c|}{ Sample state } \\
\hline \multicolumn{10}{|c|}{ Natural } & \multicolumn{10}{c|}{ Dehydrated } \\
\hline & & $i=1$ & $i=2$ & $i=3$ & $i=4$ & $i=5$ & $i=6$ & $i=7$ & $i=8$ & $i=9$ & $i=10$ \\
\hline$f_{\text {water }}^{i}$ & 0.7560 & 0.7252 & 0.7042 & 0.6756 & 0.6411 & 0.6058 & 0.5592 & 0.5020 & 0.4113 & 0.3074 & 0.1392 \\
\hline$n_{\text {dry }}^{i}$ & 1.5995 & 1.5750 & 1.5950 & 1.6011 & 1.6018 & 1.6071 & 1.6041 & 1.5960 & 1.5801 & 1.5611 & 1.5310 \\
\hline
\end{tabular}

From data in table 3 we have also calculated the mean and standard deviation of dry matter's refractive index, obtaining the following:

$$
\overline{n_{d r y}}=1.5865, \quad s d\left(n_{d r y}\right)=0.0233
$$

Considering the muscle water content values presented in tables 2 and 3, we can represent their evolution as a function of sample mass to verify if they are similar or not. Figure 3 contains these two dependences between tissue water content and sample mass during the dehydration process for the two cases studied:

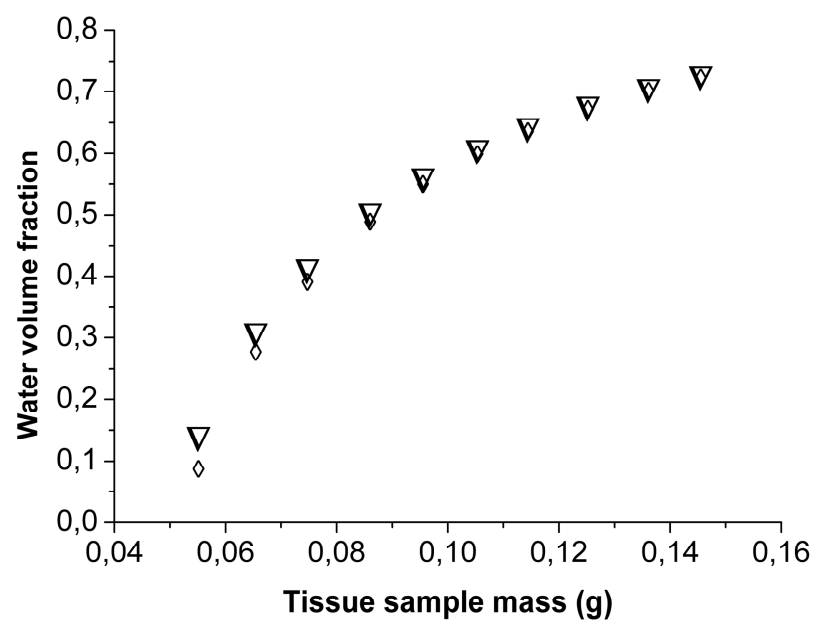

Figure 3: Dependence between tissue water content and sample mass calculated on the basis of dry matter densities measured by different research groups $\left(\diamond-\right.$ at $27^{\circ} \mathrm{C}$ and $\left.\nabla-10^{\circ} \mathrm{C}\right)$. 
As we can see from figure 3, both cases show the same behavior, although the water content values for a temperature of $27^{\circ} \mathrm{C}$ are a little higher for the more dehydrated sample. The difference is not too significant. As the tissue becomes more hydrated, we verify a greater accordance between the two cases studied, which indicates that the choice of dry matter density of bovine muscle for the two temperatures was a good choice to perform our study.

Finally, with the results from our calculations we can characterize the skeletal muscle from rat in terms of refractive indices and volume fractions of its components. Table 4 contains the data for this characterization:

Table 4: Optical characterization parameters for natural abdominal wall muscle of rat.

\begin{tabular}{|c|c|}
\hline \multicolumn{2}{|c|}{ Natural rat muscle } \\
\hline Global refractive index & 1.3980 \\
\hline Water content & $0.756 \pm 0.003$ \\
\hline Dry matter content & $0.244 \pm 0.003$ \\
\hline $\begin{array}{c}\text { Dry matter refractive index (mean from both cases calculated above based } \\
\text { on data from different groups) }\end{array}$ & $1.584 \pm 0.025$ \\
\hline Refractive index of water (calculated by equation 3) & 1.3330 \\
\hline
\end{tabular}

\section{DISCUSSION AND CONCLUSION:}

As we could see with this study, it was possible to obtain important data concerning the constitution of a fibrous tissue like the muscle and to discriminate the optical properties of its components by using a very simple experimental method. The knowledge of these parameters is of great importance for other studies, like for instance the ones of optical clearing treatments of tissues that we have also performed ${ }^{4,11}$.

By knowing the magnitude of the step in the refractive index profile of the natural muscle we could understand and quantify the refractive index matching mechanism that occurs during optical clearing with different agents like glucose or propylene glycol.

The simplicity of the experimental study that we here describe can be easily adapted to other types of biological tissues to perform a similar characterization.

The information obtained from this study is very important for the development of new optical clinical methods in the muscle and will lead to the optimization of optical clearing treatments in clinical procedures that use optical technologies.

\section{ACKNOWLEDGEMENTS}

- The authors would like to thank to the Institute of Histology and Embryology of Professor Abel Salazar (Porto University - Medical School) for all support given to accomplish the present work.

- VVT is thankful for support by the following grants:

224014 Photonics4life-FP7-ICT-2007-2

RFBR-10-02-90039-Bel_a

RF Ministry of Science and Education 2.1.1/4989, 2.2.1.1/2950, and 1.4.09

RF Governmental contracts 02.740.11.0770, and 02.740.11.0879

FiDiPro Project (40111/11), University of Oulu, Finland 


\section{REFERENCES}

[1] Tuchin, V. V., [Tissue optics: Light Scattering Methods and Instruments for Medical Diagnosis], second Ed., SPIE Press, Bellingham, WA (2007).

[2] Tuchin, V. V., "Light-Tissue Interactions", in Biomedical Photonics Handbook - chp. 3, Tuan Vo-Dihn Editor. CRC Press LLC, 2003.

[3] Tuchin, V. V., [Optical Clearing of Tissues and Blood], SPIE Press, Bellingham, WA (2006).

[4] Oliveira, L. M., Lage, A. S., Pais Clemente, M. and Tuchin, V. V., "Rat muscle opacity decrease due to the osmosis of a simple mixture", J. of Biomed. Opt. 15(5), 055004 (2010).

[5] Reinoso, R., Telfer, B. A. and Rowland, M. "Tissue water content in rats measured by dissecation", J. Pharmacol. Toxicol. Methods 38, 87-92 (1997).

[6] Oliveira, L., Lage, A. S., Pais Clemente, M. and Tuchin V. V., "Optical characterization and composition of abdominal wall muscle from rat". Opt. and Lasers in Eng. 47(6), 667 - 672 (2009).

[7] Ginzburg, S., Gromov, M. A. and Kravskaya, G. I., [Handbook on thermophysical characteristics of food products], Agropromizdat, Moscow, (1990).

[8] Latyshev, V. P., Gritsyn, M. N. and Tsyrulnikova, N. A., "Study of thermophysical properties of food products in the temperature range $77-373 \mathrm{~K}$ ". Proceedings of the all union research institute of refrigerating industry Moskow, 119-133 (1980).

[9] Kostaropoulos, A. E., [Die Wärme-and temperature litfähigkeit getrocketer Lebensmittel], Diss Karlsruhe, 128s, (1971).

[10] Maroco, J., [Análise Estatística com utilização do SPSS], Edições Sílabo, Lisboa, 27-29 (2003).

[11] Oliveira, L., [Study of the spectral transmission response of biological tissues under the influence of different osmotic agents], MsC thesis, FEUP - Faculdade de Engenharia da Universidade do Porto, Porto, (2007). 